\title{
First REPORT OF A NORTH AMERICAN INVASIVE MOSQUITO SPECIES OCHLEROTATUS ATROPALPUS (COQUILLETT) IN THE NetherLANDS, 2009
}

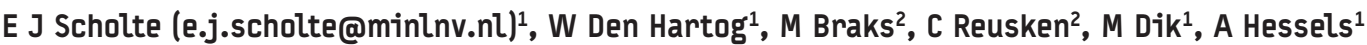 \\ 1. National Centre of Vector Monitoring, Plant Protection Service, Wageningen, the Netherlands \\ 2. Laboratory for Zoonoses and Environmental Microbiology, Centre for Infectious Disease Control Netherlands, Bilthoven, the \\ Netherlands
}

This article was published on 12 November 2009.

Citation style for this article: Scholte EJ, Den Hartog W, Braks M, Reusken C, Dik M, Hessels A. First report of a North American invasive mosquito species Ochlerotatus atropalpus (Coquillett) in the Netherlands, 2009. Euro Surveill. 2009;14(45):pii=19400. Available online: http://www.eurosurveillance.org/ViewArticle.aspx?ArticleId=19400

In late August and early September 2009, numerous larvae, pupae, and actively flying adult specimens of Ochlerotatus atropalpus were discovered in the Province of Brabant, southern Netherlands, during surveillance activities for Aedes albopictus at two trading companies that import used tires. No Ae. albopictus were found. Both companies mainly import used tires from countries in Europe, but also from North America. Oc. atropalpus is endemic to North America and has so far only been found outside of its endemic range in Europe, namely France and Italy, where it was subsequently eradicated. A preliminary modelling study shows that the weather conditions in the Netherlands are unlikely to prevent establishment of Oc. atropalpus. This species has so far only been shown to serve as a vector for virus transmission under laboratory conditions. Studies on potential human and veterinary health risks, as well as possible control strategies are currently ongoing.

\section{Introduction}

Following the discovery in 2005 of Aedes albopictus in the Netherlands at greenhouses of companies that import Lucky bamboo [1], surveillance activities to monitor this mosquito species were initiated. In 2006 a continuous surveillance programme was established and carried out by the Dutch Plant Protection Service (PPS) at these companies [2].

Gradually, other national surveillance activities for this mosquito species were established, including passive surveillance (since 2007) and active surveillance at parking lots along principle highways entering the country from the south and east (since 2008). The latter surveillance activity was initiated after reports of Ae. albopictus eggs found at parking lots in France, southern Germany, and Switzerland [3]. Since international trade of used tires is a well documented pathway dispersing Ae. albopictus around the world [4], surveillance at companies that import used tires was initiated in 2009. Except for the passive surveillance all Ae. albopictus surveillance activities are national surveys, carried out by the Plant Protection Service and funded by the Ministry of Public Health, Welfare, and Sports (Ministerie van Volksgezondheid, Welzijn en Sport, VWS).

During the surveillance at two companies that import used tires, the presence of Ochlerotatus atropalpus was observed at both companies. In Europe, the same species was found in Italy in 1996 [5] and in France in 2003 [6] and 2005 [7], but was eliminated in both countries by control measures directed against Ae. albopictus [8; F. Schaffner, pers. communication].

\section{Methods}

Two companies (subsequently called 'locations 1 and 2') were included in the survey. Both companies import used tires from airplanes, tractors, and large tires of rare sizes. One of the companies has two locations (location $2 \mathrm{a}$ and $2 \mathrm{~b}$ ). All three locations are in the south of the Netherlands, in the province of Brabant. All locations were inspected weekly.

Inspection of the sites consisted of checking tires for the presence of mosquito larvae and pupae, which were manually collected. Larvae collected during the first visit of location 1 were placed in alcohol and taken to the laboratory for molecular identification.

Larvae that were collected during the second and subsequent visits were either placed in alcohol and taken to the laboratory for morphological identification [9], or taken to the insectary to develop. A batch of eleven larvae was sent to an expert in mosquito taxonomy (F. Schaffner) at the University of Zurich, Switzerland, for morphological identification. Emerged adult mosquitoes were collected, identified morphologically, and stored in RNA-later tissue storage solution for future testing for viral RNA at the National Institute for Public Health and the Environment (Rijksinstituut voor Volksgezondheid en Milieu, RIVM). Molecular identification of the larvae consisted of sequencing the cytochrome oxidase 1 (CO1) gene, a mitochondrial gene with a relatively high mutation rate which renders it suitable for molecular species differentiation tests.

In total, 23 visits were carried out (eleven at location 1, eight at location $2 \mathrm{a}$, and four at location $2 \mathrm{~b}$ ). On seven visits after the first inspection (three at location 1 and four at location 2a), the inspector was accompanied with a colleague who manually collected actively flying mosquitoes using hand-held mouth aspirators (transparent tubes with mesh wire to prevent inhalation of mosquitoes, used to capture live mosquitoes). These were brought to the laboratory, stored at $-20^{\circ} \mathrm{C}$ for at least one hour, identified morphologically, pinned, and labelled to be kept as reference material. 
Additionally, after the first visit, 20 oviposition traps and several adult traps (three $\mathrm{CO}_{2}$ traps with octenol and, at locations 1 and 2a, two additional BG Sentinel traps) were placed in the immediate surroundings of all three locations, in zones of approximately $1 \mathrm{~km}^{2}$ to determine possible spread of the species.

In order to predict whether Oc. atropalpus could become established in the Netherlands, a modelling study was carried out using 'Climex' [10], a software designed to match climates in ecology, which is used to carry out rapid, reliable assessment of the risks posed by the introduction of different organisms and to predict locations to which they could spread and become established. Parameters (temperature, moisture, heat stress, dry stress, wet stress, and degree-days) for suitable areas for Oc. atropalpus establishment were based on parameters of the known original distribution area [11] and determined by adjusting these parameters until they fitted the original distribution area.

\section{Results}

\section{First visit}

Initially, only location 1 was inspected. During that visit, seven larvae were retrieved. Sequence results for the seven larvae were negative for Ae. albopictus. However, the sequence of the $\mathrm{CO} 1$ gene from all seven specimens matched to 98.6-99.0\% the CO1 sequence of Oc. atropalpus stored in GenBank.

\section{Second and subsequent visits}

Identification of Oc. atropalpus at location 1 prompted further inspection visits to this location as well as visits to locations $2 \mathrm{a}$ and $\mathrm{b}$. During the second visit at location 1, 11 Culicidae were collected. A taxonomy expert confirmed five of them as Oc. atropalpus by morphological identification (the others were Culex pipiens $(n=5)$ and Culiseta annulata $(n=1))$.

Surveillance activities that were carried out in all three locations after the first visit (at location 1 ), resulted in the finding of numerous larvae and pupae. Approximately 500, 250, and 100 larvae were collected from locations $1,2 \mathrm{a}$ and $2 \mathrm{~b}$ respectively. At locations 1 and $2 a$, larvae were found in almost every tire that contained water. At these two locations, also actively flying adult mosquitoes were collected.

Oc. atropalpus was present at two of the three locations (locations 1 and 2a). Not all larvae collected have developed into adults yet, but from the data that have been analysed so far, approximately half of the emerged adults were morphologically diagnosed as Oc. atropalpus. The other were Culex pipiens/ torrentium and, occasionally, $C$. annulata. The same is true for the actively flying adults that were collected. To date, no Oc. atropalpus eggs have been collected in any of the oviposition traps placed in the surrounding areas. Virus detection tests have yet to be carried out on the emerged adults stored in RNA-later solution.

At none of the three locations that were visited in this survey, Ae. albopictus was detected.

\section{Climex model study}

Using the 'match climates' module in 'Climex' software, parameters were set to fit the endemic geographic distribution of Oc. atropalpus, as described in [11] (southeastern Canada and mid-east-eastern United States). The model used this set of parameters to compare with meteorological data from locations in other areas of the world to predict likely areas where Oc. atropalpus could become established. This preliminary study shows that the climatological conditions in the Netherlands are not a limiting factor for establishment of Oc. atropalpus (see Figure).

\section{Discussion and conclusion}

The most likely introduction pathway of Oc. atropalpus from North America into the Netherlands is the passive transport of eggs through the import of used tires from airplanes, tractors, or soillifting vehicles. It is unlikely that the introduction has taken place this year, considering that tires containing Oc. atropalpus were found scattered over the premises of the two inspected companies, and only about $2 \%$ of the companies' tires are imported from overseas. Possibly, Oc. atropalpus was introduced several years ago. The fact that it was found in two different companies, separated by $100 \mathrm{~km}$, could be explained by the fact that they occasionally exchange tires. Another possibility is that separate introductions

F I G U R E

Climex model study for Ochlerotatus atropalpus
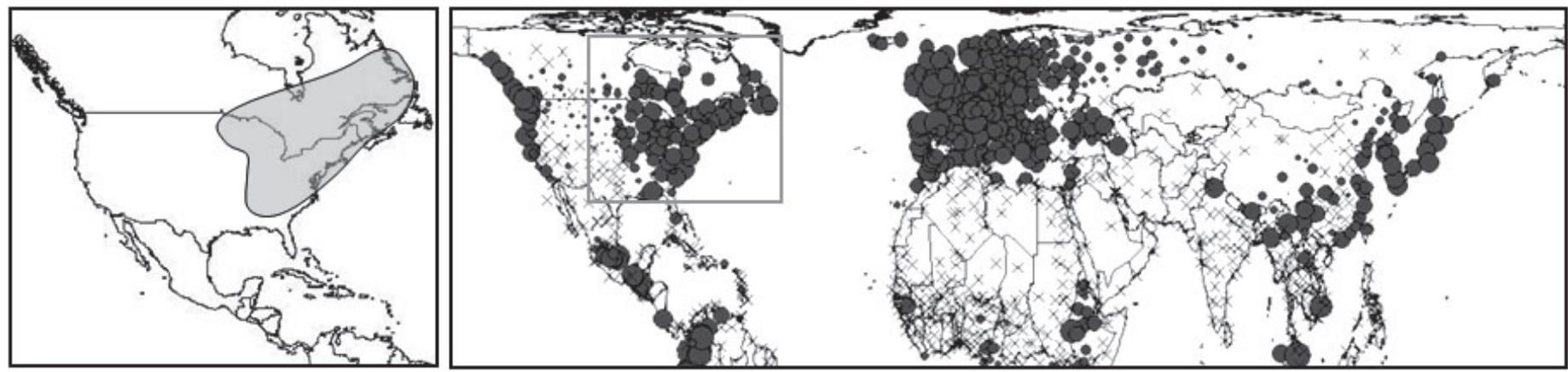

The grey area in Figure A shows the endemic geographic distribution of Ochlerotatus atropalpus [11; included here with permission from Journalof Genetics: Szymczak et al., 1986; J. Genet. 65(3):193-204, published by the Indian Academy of Sciences, Bangalore, India]. Areas with similar meteorological conditions as in the grey area (A) are depicted as dark grey dots in B (the larger the dot, the better the fit), thus predicting a relatively high likelihood that Oc. atropalpus could establish in that area. In contrast, crosses indicate areas with very low meteorological similarities to the area depicted in $\mathrm{A}$, predicting that in such an area this mosquito species is unlikely to be able to establish. 
of this species have occurred in the past. The species has been introduced into Europe on at least three separate occasions, once in Italy and twice in France, through import of used tires [5,6,7]. However, it is unlikely that the specimens found in the Netherlands were imported from other European companies since the three aforementioned known foci of Oc. atropalpus were successfully eradicated [8, F. Schaffner, pers. communication] and new introductions have not been reported since 2005.

The first results of the oviposition and adult traps in the surrounding areas of the two infested sites suggest that the species has not spread to the immediate surroundings. We are currently investigating whether the species (or other invasive mosquito species) are present at companies that import used truck and bus tires.

The results of the preliminary modelling study imply that

Oc. atropalpus could become established in large areas of Europe.

In the field, Oc. atropalpus is not considered an important vector of infectious diseases. However, under laboratory conditions, the species is a competent vector for West Nile virus, Japanese encephalitis virus (JEV), Saint-Louis encephalitis virus (SLEV), La Crosse encephalitis virus (LACV), Murray valley encephalitis virus (MVEV), Western equine encephalitis virus (WEEV), and Eastern equine encephalitis virus (EEEV) $[12,13]$. SLEV and LACV can be transmitted transovarially by Oc. atropalpus [14,15], with laboratory studies that reported infection rates of up to $13.9 \%$ in adults that derived from eggs that were laid by LACV-infected females [15].

Oc. atropalpus was reported only once to be positive for virus infection: in one pool positive for WNV in the United States in the year 2000 , out of 515 positive WNV pools consisting of 14 species [16]. It is possible that SLEV and LACV came into the Netherlands with the import of this mosquito species, but because of the limited role of Oc. atropalpus in the epidemiology of these viruses in its area of origin, this likelihood is considered very low. However, a role of the species in the spread of pathogens cannot be excluded.

The Dutch Ministry of Public Health, Welfare, and Sports considers this invasive mosquito species to be an 'unwanted organism' for the Netherlands, based on its putative role in the spread of infectious diseases important for public health. Control strategies are currently being investigated, including adequate treatment of used tires upon arrival and/or roofed storage of tires.

The aim of the surveillances at the tire import companies was initiated to monitor the presence of Ae. albopictus. The finding of Oc. atropalpus shows that other invasive mosquito species may be introduced as well and underlines the importance of mosquito surveillance systems.

\section{Acknowledgements}

We would like to thank F Schaffner (University of Zurich, Switzerland), G O'Meara (University of Florida, United States), G Majori (Istituto Superiore di Sanità, Rome), A Drago (Entostudio, Italy), T Howard (California Department of Public Health, United States), M Latham (Manatee County Mosquito Control District, United States), LP Lounibos (University of Florida, United States), M Van de Homberg (Centre for Monitoring of Vectors, the Netherlands), and S Bhagirath (Centre for Monitoring of Vectors, the Netherlands).

\section{References}

1. Scholte EJ, Jacobs F, Linton YM, Dijkstra E, Fransen J, Takken W. First record of Aedes (Stegomyia) albopictus in the Netherlands. Euro. Mosq. Bull. 2007; 22: 5-9.

2. Scholte EJ, Dijkstra E, Blok H, De Vries A, Takken W, Hofhuis A, et al. Accidental importation of the mosquito Aedes albopictus into the Netherlands: a survey of mosquito distribution and the presence of dengue virus. Med. Vet. Entomol. 2008; 2(4)2: 352-358.

3 European Centre for Disease Prevention and Control. Development of Aedes albopictus risk maps. Technical report. Stockholm: European Centre for Disease Prevention and Control; May 2009. Available from: http://www.ecdc. europa.eu/en/publications/Publications/0905_TER_Development_of_Aedes_ Albopictus_Risk_Maps.pdf

4. Enserink M. A mosquito goes global. Science. 2008;320(5878):864-6.

5. Romi R, Sabatinelli G, Savelli LG, Raris M, Zago M, Malatesta R. Identification of a North American mosquito species, Ochlerotatus atropalpus (Diptera: Culicidae), in Italy. J. Am. Mosq. Control Assoc. 1997; 13(3):245-6.

6. Adege-EID Méditerranée. Surveillance committee of Aedes albopictus - Meeting report at DGS, Paris, 17 Dec. 2003. Montpellier: Entente interdépartementale pour la démoustication du littoral (EID) Méditerranée; 2003. French.

7. Adege-EID Méditerranée. Éléments entomologiques relatifs au risque d'apparition du virus Chikungunya en métropole. [Entomological facts related to the risk of appearance of chikungunya virus in Metropolitan France]. Study report. Montpellier: Entente interdépartementale pour la démoustication du littoral (EID) Méditerranée; March 2006. French.

8. Romi R, Di Luca M, Majori G. Current status of Aedes albopictus and Aedes atropalpus in Italy. J Am Mosq Control Assoc. 1999;15(3):425-7.

9. Schaffner F, Angel G, Geoffrey B, Hervy J-P, Rhaiem A, Brunhes J. The mosquitoes of Europe. CD-ROM. Montpellier: Institut de Recherche pour le Développement/Entente interdépartementale pour la démoustication du littoral (EID) Méditerrannée ; 2001.

10. CLIMEX - Software to predict the effects of climate on species. Hearne Scientific Software.

11. Szymczak LJ, Hilburn LR, Rai KS. Genetic differentiation in the Aedes atropalpus complex. J Genet. 1986;65(3):193-204.

12. Turell MJ, O'Guinn ML, Dohm DJ, Jones JW. Vector competence of North American mosquitoes (Diptera: Culicidae) for West Nile virus. J Med Entomol. 2001;38(2):130-4.

13. King WL, Bradley GH, Smith CN, MCDuffie WC. A handbook of the mosquitoes of the southeastern United States. Handbook 173. Washington, DC: US Department of Agriculture; 1960.

14. Pelz EG, Freier JE. Vertical transmission of St. Louis encephalitis virus to autogenously developed eggs of Aedes atropalpus mosquitoes. J Am Mosq Control Assoc. 1990;6(4):658-61.

15. Freier JE, Beier JC. Oral and transovarial transmission of la Crosse Virus by Aedes atropalpus. Am J Trop Med Hyg 1984;33(4):708-14.

16. Nasci RS. Mosquito species associated with West Nile Virus in the United States, 1999-2001: Implications for virus transmission. National West Nile Conference; 2002. Available from: http://www.cdc.gov/ncidod/dvbid/westnile/ conf/pdf/p1-nasci.pdf. 